starting treatment while asymptomatic but with low CD4 counts or at the start of minor symptoms. This reflects a greater optimism about treatment and an impression from trial subgroup analyses that all patients with CD4 counts below 350, with or without symptoms, will benefit.

Thirdly, the studies have provided some validation of the virological and immunological markers of HIV disease in predicting clinical benefit: the greater effect on these of combination treatment does translate into greater clinical benefit. Whether this finding can be extrapolated beyond treatment with nucleosides remains unclear, though markers ought theoretically to be valid for drugs acting at any point in the virus life cycle. When combined with nucleosides, both non-nucleoside reverse transcriptase inhibitors (such as nevirapine, loviride, and delavirdine) and protease inhibitors (such as saquinavir, ritonavir, and indinavir), show substantially greater effects on markers than monotherapy. Although data from phase III clinical trials are awaited (a preliminary conference report suggests that ritonavir also affects clinical end points), these drugs are starting to be more widely available.

Finally, and more problematically, the studies have raised unanswered questions about the future management of the large number of patients who have already received prolonged nucleoside monotherapy. It seems unlikely that other nucleoside combinations (such as zidovudine and lamivudine (3TC)) will be more effective in such patients, as they have a broadly similar effect on disease markers. In principle, patients who have already received nucleoside monotherapy have three options: to continue monotherapy, to change to a combination with drugs acting at different sites (either non-nucleoside reverse transcriptase inhibitors or protease inhibitors), or to use more than two drugs.

Patients who are doing well with monotherapy may be inclined to stick with it until other options are clarified. Patients who want to change may be so inclined because of new HIV disease events or a fall in CD4 count. Few trial data are available to help them make rational choices, because most large scale trials have focused on patients who have never received anti-retroviral drugs. This is understandable when clear cut answers are sought for scientific purposes or licensing of products, but it has left a large group of patients effectively disenfranchised.

For patients taking monotherapy who want to add another drug to their regimen, arguably the best option would be to enter a large scale comparative clinical trial of the most promising of these combinations. It remains to be seen whether bodies such as Britain's Medical Research Council or the National Institutes of Health in the United States can achieve timely agreement from all relevant parties on a suitable protocol. In the long run the cost of not doing so will be greater, because of expenditure on inadequately tested regimens.

Meanwhile, purchasers and providers of health care are assessing the costs of applying the results of Delta and ACTG175, which are likely to increase the costs of HIV drugs by $50-75 \%$. While there is much talk of evidence based medicine in health commissioning, the only comment so far in Britain has been that the cost of combination treatment would have to be found from within existing allocations. Yet indications are that these allocations are to be reduced substantially, despite the still increasing caseload (albeit less than the more pessimistic projections). Robust discussions can be expected on this in the coming months. A research strategy should be developed which will ensure well informed clinical decision making and cost effective prescribing.

ANTHONY J PINCHING

Professor of immunology

St Bartholomew's and the Royal London School of Medicine and Dentistry, London EC1A 7BE

1 Fischl MA, Richman DD, Grieco MH, Gottlieb MS, Volderding PA, Laskin OL, et al. The efficacy of azidothymidine (AZT) in the treatment of patients with AIDS and AIDS-related complex. $N$ Engl F Med 1987;371:185-91.

2 Fischl MA, Richman DD, Hansen N, Collier AC, Carey JT, Para MF, et al for the AIDS Clinical Trials Group. The safety and efficacy of zidovudine (AZT) in the treatment of subjects with mildly symptomatic human immunodeficiency virus type 1 (HIV) infection. Ann Intern Med 1990;112: 727-37.

3 Sande MA, Carpenter CCJ, Cobbs CG, Holmes KK, Sanford JP, for the NIAID State-of-the-Art Panel on Anti-Retroviral Therapy for Adult HIV-Infected Patients. Anti-retroviral therapy for adult HIV-infected patients: recommendations from a state-of-the-art conference. $\mathscr{F} A M A$ 1993;270:2583-9.

4 Volberding PA, Lagakos SW, Koch MA, Pettinelli C, Myers MW, Booth DK, et al for the AIDS Clinical Trials Group of the NIAID. Zidovudine in asymptomatic human immunodeficiency virus infection. N Engl F Med 1990;322:941-9.

5 Concorde Coordinating Committee. Concorde: MRC/ANRS randomised double-blind controlled trial of immediate and deferred zidovudine in symptom-free HIV infection. Lancet 1994;343: 871-81.

\title{
Human papillomavirus infection
}

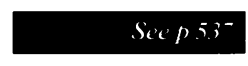

\section{Pathogenesis suggests new strategies for preventing and treating cervical dysplasia and cancer}

Cervical cancer is estimated to cause 500000 deaths each year worldwide. The public health impact of controlling precursor cervical lesions and cancer is potentially huge, especially in developing countries, where the incidence of cervical cancer approaches 40 per 100000 women. ${ }^{1}$ Advances in cellular and molecular biology and immunology enable detailed investigation of disease pathogenesis. These advances help our understanding of the role that human papillomaviruses play in premalignant and malignant lesions of the cervix and have important ramifications for the way we diagnose, screen, and treat associated disease. In this issue of the $B M F$ Lehtinen and colleagues report on a study that directly applied molecular immunology to clinical and epidemiological medicine to support existing scientific evidence of human papillomavirus and its association with invasive cervical cancer. $^{2}$

Papillomaviruses are a genera of viruses grouped together by their tumorigenicity and homogeneity of DNA. They infect a wide variety of vertebrates, including man. To date, more than 70 types of human papillomavirus have been described. Each type shows a particular tropism to specific anatomic sites. Cutaneous infections of the skin and mucosal infections of anogenital, oral, and respiratory epithelia are common. ${ }^{1}$ Attention has focused on the association between anogenital infection with human papillomavirus and the development of cervical dysplasia and invasive cervical cancer. In a study of over 2600 cervical smears Lorincz et al reported that highly oncogenic DNA from human papillomavirus type 16 was found in $47 \%$ of high grade squamous intraepithelial lesions and $47 \%$ of invasive cancers by Southern blotting. ${ }^{3}$

Genomic human papillomavirus DNA is functionally divided into early $(\mathrm{E})$ and late $(\mathrm{L})$ genes. The early genes are responsible for DNA replication, transcriptional regulation, and transformation. The late genes encode the major and minor capsid proteins. Early gene products act as onco- 
proteins. These proteins, expressed in all tumours, inactivate the cellular tumour suppressor gene products $\mathrm{p} 53$ and $\mathrm{pRb}$, causing uncontrolled cellular proliferation. Early genes are necessary but not sufficient for malignant conversion. Modification of early gene regulation by host cells seems to be required for malignant progression. ${ }^{4}$ Cervical cancers associated with human papillomavirus often exhibit a loss or reduction of allelic expression of critical major histocompatibility complex class I molecules. Down regulation of these molecules, which are intimately involved in recognition and surface presentation of antigens, may explain why some cancers escape cell mediated immune surveillance. ${ }^{4}$ After infection, development of dysplasia and cancer is not constant and ordinarily occurs over several years.

Recently, the ability to purify recombinant virus-like particles, as well as capsid proteins of selected human papillomaviruses that mimic conformational and neutralising epitopes of native virions, has fostered an explosion of applications..$^{6-9}$ Detailed seroepidemiological studies using these proteins, like that of Lehtinen et $a l^{2}$ can now be accomplished. These data confirm the role that selected mucosotropic anogenital human papillomavirus types have in the aetiology of cervical cancer. ${ }^{10}$ Beagle dogs immunised with virus-like particles of canine oral papillomavirus are completely protected by neutralising antibodies from developing mucosal papillomas. ${ }^{11}$ This animal model clearly suggests that virus-like particles of human papillomavirus are candidates for prophylactic subunit vaccines, since they induce protective antibodies in the host and contain no potentially oncogenic viral DNA. Finally, Feltkamp et al reported that injection of peptide fragments of early genes into mice induced protective cell mediated immune responses against formation of tumours. ${ }^{12}$ Stimulation of cell mediated immunity is an attractive therapeutic strategy to augment tumour rejection and regression.

As we continue to unravel the cellular and molecular mechanisms responsible for carcinogenesis and its relation to infection with human papillomavirus, targeted strategies for prevention and treatment of disease will become reality. These strategies may affect gene regulation or protein expression or they may exploit humoral and cell mediated immunity to effect prevention and rejection of tumours.

JEFFREY F HINES

Gynecologic oncologist

Gynecologic Oncology Service, Department of Obstetrics and Gynecology, Brooke Army Medical Center, Fort Sam Houston, Texas, USA

SHIN-JE GHIM Research assistant professor of pathology A BENNETT JENSON Professor of pathology

Department of Pathology,

Georgetown University Medical Center,

Washington, District of Columbia,

USA

1 Jenson AB, Lancaster WD. Papillomaviruses and human cancer. Boca Raton: CRC Press, 1990.

2 Lehtinen M, Dillner J, Knekt P, Luostarinen T, Aromaa A, Kirnbauer R, et al. Serologically diagnosed infection with human papillomavirus type 16 and risk for subsequent development of cervical carcinoma: nested case-control study. BMF 1996;312:537-9.

3 Lorincz AT, Reid R, Jenson, AB, Greenberg MD, Lancaster WD, Kurman RJ. Human papillomavirus infection of the cervix: relative risk associations of 15 common anogenital types. Obstet Gynecol 1992;79:328-37.

4 Schlegel R. Papillomaviruses and human cancer. Seminars in Virology 1990;1:297-306.

5 Connor ME, Stern PL. Loss of MHC class I expression in cervical carcinomas. Int $f$ Cancer 1990;46:1029-35.

6 Ghim S, Jenson AB, Schlegel R. HPV1 L1 protein expressed in cos cells displays conformational epitopes found on intact virions. Virology 1992;190:548-52.

7 Kimbauer R, Booy F, Cheng N, Lowy DR, Schiller JT. Papillomavirus L1 major capsid protein self-assembles into virus-like particles that are highly immunogenic. Proceedings of the National Academy of Sciences, USA 1992;89:12180-4.

8 Hines JF, Ghim S, Christensen ND, Kreider JW, Barnes WA, Schlegel R, et al. Role of conformational epitopes expressed by human papillomavirus major capsid proteins in the serologic detection of infection and prophylactic vaccination. Gynecol Oncol 1994;55:13-20.

9 Hines JF, Ghim S, Christensen ND, Kreider JW, Barnes WA, Schlegel R, et al. The expressed L1 proteins of HPV-1, HPV-6, and HPV-11 display type specific epitopes with native conformation proteins of HPV-1, HPV-6, and HPV-11 display type specific epitopes with native conforma
and reactivity with neutralizing and nonneutralizing antibodies. Pathobiology 1994;62:165-71.

10 Bosch FX, Manos MM, Munoz N, Sherman M, Jansen AM, Peto J, et al. Prevalence of human papillomavirus in cervical cancer: a worldwide perspective. $\mathcal{f}$ Natl Cancer Inst 1995;87: 796-802.

11 Suzich JA, Ghim S, Palmer-Hill FJ, White WI, Tamura JK, Bell JA, et al. Systemic immunization with papillomavirus $\mathrm{L} 1$ protein completely prevents the development of viral mucosal papillomas. Proceedings of the National Academy of Sciences, USA 1995;92:11553-7.

12 Feltkamp MC, Smits HL, Vierboom MP. Vaccination with cytotoxic T lymphocyte epitopecontaining peptide protects against a tumor induced by human papillomavirus type 16transformed cells. Eur f Immunol 1993;23:2242-9.

\section{Case management: a dubious practice}

\section{Underevaluated and ineffective, but now government policy}

American psychiatrists visiting Britain will experience a sense of déja vu when they encounter the recent clutch of community care "initiatives." They will soon spot that "care management" and the "care programme approach" are no more than a rehash of "case management," an old American idea. From politeness they will probably refrain from telling their hosts that there is little reason to believe that case management works.

Case management arose in the United States in response to the dispersal of psychiatric and social care that followed the closure of large mental hospitals. The basic idea was that a designated person, the "case manager," would take special responsibility for a "client" in the community. The case manager would assess the client's needs and ensure, through a care plan, that suitable services were provided to meet them. The case manager would also monitor the provision of these services and maintain contact with the client. ${ }^{1}$

From the beginning the literature on "case management" has been bedevilled by a tendency to lump two different approaches under one name. The first approach could be described as "standard" case management. This is a low intensity approach in which case managers offer a largely "office based" service, brokering interventions from other agencies. Each case manager has a case load of 30 or more clients whom they see infrequently. The standard approach has several variations in which case managers take a more therapeutic role and carry smaller case loads. Yet even these "clinical" case managers tend to offer fairly low intensity intervention.

The second approach lumped under the term "case management" is more properly described as "assertive community treatment." This bears little resemblance to "standard" case management. The assertive community treatment approach is provided by a dedicated multidisciplinary team of mental health professionals that generally includes a psychiatrist. The overall patient-staff ratio is low (about 10:1) and the level of face to face contact is high. The importance of individual case loads is played down; instead team members work with patients as and when their particular skills are required. The team concentrates on avoiding hospital admission and developing patients' independent living skills. Assertive efforts are made to retain contact with patients. ${ }^{2}$ 